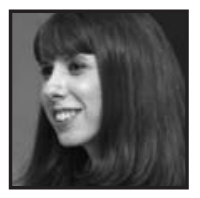

\title{
Arts-Based Research as a Pedagogical Tool for Teaching Media Literacy: Reflections From an Undergraduate Classroom
}

\author{
Patricia Leavy, Stonehill College
}

\section{ABSTRACT}

In this paper I review my use of arts-based research practices as a set of pedagogical tools for teaching media literacy in an undergraduate sociology course titled "Images \& Power: Popular Culture." The paper details how I incorporated arts-based research into my course as a part of my holistic and participatory approach to media literacy. Arts-based practices are an effective tool for fostering critical consciousness. Samples of student work are included. ${ }^{1}$

\section{Introduction \\ "Man of the Hour" by Sean Lynch}

e's been pulled off stage without a word or a notion of what's going on
He was the last hope, the last chance for men of times gone by to define
who we are But now it's only those men who define women and those men who resent women

Who are defining who I am and that's not what I want or why I'm here

I'm here because I want a chance to speak for myself And I have that chance 
But most of the time those same women who are defined by those same men don't get it

That one chance to really say or do or be or hear or act in a way that is What they are

And they let women define them until all the men and all the women are defined by one thing

Or another and there is nothing unique and nothing different

It is either this or that or nothing at all

The preceding poem was written by my student, Sean Lynch, as a part of his final paper in my undergraduate course,"Images \& Power: Popular Culture."The poem explores his struggles with social constructions of masculinity and femininity and how those constructions confine and limit people his age. In the poem he tries to address how these constructions impact young men and women differently and how he does not want to be defined by them or to use them to define others. It is a powerful personal statement of awareness and resistance. Moreover, it illustrates the emergence of a critical consciousness, the ultimate goal in my course.

In this paper I review my use of arts-based research practices as a set of pedagogical tools for teaching media literacy. Eisner (2008) suggests that the concept of literacy can be re-conceptualized to recognize the multiple ways in which people can be literate or "multi-literate" (p.27).I make a case for specifically using the arts to teach media literacy. I used arts-based practices in an undergraduate sociology course on critical approaches to popular culture. In order to explain the effectiveness of this approach to media literacy education, I begin with a brief review of my teaching and learning goals. Then I offer brief literature reviews on media literacy and arts-based research, respectively. The remainder of the paper details how I incorporated artsbased research into my course as a part of a participatory approach to media literacy. I include examples of student work. I conclude by suggesting that arts-based research can be a powerful tool for teaching media literacy.

\section{My Teaching and Learning Goals}

To think about effective teaching on its own is to put the cart before the horse. Teaching is always linked to learning and learning must be at the center of 
teaching efforts. Finkel (2000) suggests that the dominant model of teaching is based on telling:"the sage on the stage," so to speak, where professors lecture and students learn through listening, copious note taking, and studying. Research indicates that traditional models of lecturing do not produce significant, long-lasting learning (Finkel, 2000). Finkel challenges the dominant model by redirecting attention to learning:

Good teaching is the creating of those circumstances that lead to significant learning in others ... good teaching must be conceived in terms of learning ... [this] formulation reminds us of the primacy of learning, not teaching, in education. Learning is the end, teaching is a means to that end. (p. 8)

Similarly, Brookfield (2006) writes: "Skillful teaching is whatever helps students learn (p. 17)"-again, emphasizing student learning. Eisner (2008) notes that how something is taught impacts what students learn. Encouraging professors to think beyond traditional lectures, Finkel asks: "What other shapes could teaching take?" (2000, p. 1). Through a process of participating in teaching seminars and pedagogy conferences, I have come to consider "new shapes" for my own practices. In recent years I too have come to think extensively about my profession, teaching, and how to best produce meaningful student learning. When considering other forms for teaching, I am influenced by hooks' (1994) focus on the importance of making students "active participants" in their learning process.

Based on my own experiences teaching, as well as my review of teaching and learning scholarship, I suggest that the fundamental issue professors must consider as they choose pedagogical strategies is: the alignment of teaching methods with learning goals. In my discipline of sociology, this is clear in the research process; research methods are merely tools that are selected because of their utility for addressing particular issues. Put differently, you do not use a wrench to bang a nail into the wall if you have access to a hammer. Standard approaches to teaching cannot simply be employed irrespective of particular desired learning outcomes. Rather, desired learning outcomes must be identified and teaching practices selected that best facilitate those goals. This is a problem-centric approach to teaching.

In reflecting on the goals of my courses I have come to realize that in a fouryear college setting, working exclusively with undergraduates, and within sociology, my goals typically are not content based, or at least not exclusively so. Rather, my primary goals are to help students develop critical thinking skills and a critical consciousness. As a feminist, my commitment to fostering critical consciousness is at the forefront as I construct courses and navigate with my students through them. In 
this regard I emphasize issues of race, class, gender and sexuality. I aim for students to come to a deeper understanding of social power, and how it operates through ideologies, and impacts the psychic life of individuals. A heightened critical consciousness is a necessary precondition for this kind of reflexivity. My secondary goal is to foster self-expression and personal growth. The question then becomes: How do I best achieve my goals? In other words, what pedagogical strategies best align with my desired learning outcomes?

I teach an undergraduate elective course called "Images \& Power: Popular Culture."The course is cross-listed as a sociology and gender studies course and, over the ten or so years I have been teaching the course, I typically get a mix of students from across the disciplines. Students read a variety of essays and articles presenting critical perspectives on various dimensions of popular culture: advertising, television, toys/games, globalization, movies, music, and so on. Most of the readings have race, class, gender, and/or sexuality perspectives looking at how popular culture can be used to create and reify existing relations of power or to subvert and resist those relations. In short, the goal of the class is to raise students' critical consciousness. In order to reach this goal, I adopt a critical media literacy approach to the course, helping students to become sensitized to the pop culture images and messages circulating in their environment.

\section{Media Literacy}

Media literacy projects propose that in order to be literate in contemporary society which is media saturated, people must be given strategies for reading media. Media literacy education assists people in understanding the ways in which messages are communicated to audiences through advertising, narrative, and images in the media. Media literacy programs typically have two main goals: to teach people to critically analyze mass media, and to offer people tools to develop new ways of putting their own messages into the multimedia network. Brown (1998) suggests people need to develop "media logic" about how they use and relate to their mediated environment. Learning about the strategies of the media can better enable individuals to question what is portrayed in media images and how they as individuals are impacted by media narratives (often in insidious ways). For example, media literacy challenges people to take media consumption seriously instead of assuming media is trivial and therefore not worthy of their focused attention. Media literacy projects cannot disavow the pleasure people take in their media consumption, but rather must address this complicated issue head on. One way to do this is to address people's process of media selection. 
This spotlight on "media logic" draws people's attention to the ideologies, assumptions and values that circulate via media images. Research indicates that developing new ways to process these messages - critically, rather than passivelymay intervene in the absorption of unhealthy images (Berel \& Irving, 1998; Levine \& Smolak, 1998; Levine, Piran, \& Stoddard, 1999). Therefore media literacy projects aim to make media consumers active rather than passive (Brown, 1998, p. 47). This is not to imply that media literacy simply inoculates people against harmful messages. Media literacy aims to sensitize people to their media consumption.

For example, and as related to my feminist agenda, media literacy may seek to help people unravel idealized versions of femininity. Research indicates that while media literacy cannot inoculate girls and women from the harmful influence of idealized images, it can foster vital critical thinking skills. Irving and Berel (2001) studied the effectiveness of short-term media literacy on college women's resilience to media images of femininity. They found that media literacy programs that include a fifteenminute educational feminist video about images of women in advertising resulted in "greater media skepticism" in female viewers (p. 109).

Scholarship suggests a vital link between media literacy and "empowerment education." I briefly elaborate on this connection because it is central to how I approach media literacy in Images \& Power.

Media literacy is an integral component of "empowerment education," which is based on the premise that "population health and well-being are intimately tied to, and are consequences of, power and powerlessness" (Bergsma, 2004, p. 153). Health education and prevention research indicates that empowerment education is an effective model for both individual and social change, particularly for vulnerable or marginalized groups. Empirical research shows that empowerment education is most effective when it creates "resilience" towards "unhealthy" media messages by fostering "critical thinking skills" (2004). "Consciousness-raising" is a necessary first step towards empowerment education and media literacy can provide a consciousness-raising experience (2004).

\section{Arts-Based Research Practice}

I view my Images \& Power course, like all of my courses, as an exercise in empowerment education. My hope is that students will develop a critical consciousness for two main reasons: to develop a social justice perspective, and so that they can become empowered to make reflexive and self-affirming choices. Both goals are 
products of the feminist sensibility I bring to my courses. In Images \& Power these goals are achieved by teaching media literacy.

Arts-based research practices (ABR) or arts-based educational research (ABER), on the rise since the 1970s, have developed in an interdisciplinary and multidisciplinary methods context, requiring the crossing and blurring of disciplinary boundaries, cross-disciplinary collaborations and reevaluations of valid research and pedagogical practices.

Arts-based research practices are a set of methodological tools used by qualitative researchers across the disciplines during all phases of social research including data collection, analysis, interpretation, and representation. These emerging tools adapt the tenets of the creative arts in order to address social research questions in holistic and engaged ways in which theory and practice are intertwined. Arts-based methods draw on literary writing, music, performance, dance, visual art, film and other media. Representational forms include but are not limited to short narratives, novels, experimental writing forms, poems, collages, paintings, drawings, performance scripts, theatre performances, dances, documentaries, and songs (Leavy, 2009, pp. 2-3).

The arts have the capability to be evocative, provocative, emotional, and at their best, arresting. Moreover, the arts can "stimulate, refine, and convey meanings that cannot be expressed in any other form of representation" (Eisner, 2008, p. 23). Arts-based practices offer the following possibilities: unsettling stereotypes, building coalitions across difference, promoting dialogue, cutting through jargon and other prohibitive barriers, extending public sociology, building critical consciousness, raising awareness, and expressing feeling-based dimensions of social life (such as love, loss, and grief) (Leavy, 2009). With respect to unsettling stereotypes and raising awareness, the arts can be used to jar people into seeing things differently. With respect to promoting dialogue, the arts open up a multiplicity of meanings (instead of closing off possible meanings). Finally, art can speak to diverse audiences irrespective of education, social class, and other status characteristics.

I started using arts-based practices in my research, here and there, long before I had heard the term. I ended up discovering the field of arts-based research during my research into innovative approaches to research methodology.

In recent years I have turned to arts-based research practices as a part of my holistic qualitative research practice (primarily using poetic forms of data analysis and representation). Among the many benefits, I have found that incorporating my 
research poems into conference presentations as well as class lectures seems to quickly serve as a consciousness-raising experience, at times based on resonance and at times based on the evocative disruption of stereotypes or assumptions. These experiences encouraged me to think about how my students could explore ABR as a hands-on means of consciousness-raising. Greene (2008) notes that imagination is vital to consciousness-raising and thus advocates "aesthetic education," which motivates students to actively participate in their learning. In this vein, Eisner (2008) suggests that open-ended tasks promote imagination. Two studies relying on arts-based participatory research strategies pushed my thinking about how to use ABR in my courses.

First, Knowles and Thomas (2002) conducted a study exploring students' sense of place and space in secondary school. The researchers asked a sample of school students to use art to convey how they see themselves and what they think about school as a place to be. Students were asked to use one or more of seven multimedium options: self-portrait, memory map, photo of place, photo of self in place, narrative, found object, and two- or three-dimensional artwork. Students were also asked to textually describe and explain their art. The artwork presented great insights into the students' experiences that may not have been captured via traditional prose alone. Many students focused on issues of "fitting in." For example, one student created a self-portrait that she partly explained as follows: "My portrait is cropped closely around my face to represent the lack of freedom I feel at school" (p. 127). I see this work as implicitly containing threads of empowerment education.

Hershorn's (2005) study investigating how students in urban school settings feel about violence in their environments also fostered my thinking about $A B R$ in the classroom. Hershorn asked students to, in any way they chose, create a visual picture of "violence and destructive behavior from their own lives" (p. 2). Many of the students incorporated media images of war and bloodshed into their art. Hershorn had not anticipated these data to emerge. As a result she added a second phase to her research about the impact of media images of September $11^{\text {th }}$ and the Iraq War. Hershorn's research makes important linkages between global crises and their impact on individuals' psyches. The nature of this study directed my thinking towards my Images \& Power course, in which I apply a critical feminist approach to media literacy. 


\section{Using ABR in my Undergrad Pop Culture Course}

In the past, in addition to course readings I have turned to films as a pedagogical tool to heighten students' awareness as well as to illustrate and punctuate course readings. I think many professors use films as a "reliable standby." However, given my research with arts-based approaches to inquiry, I wondered if the capabilities ABR has for raising critical consciousness could be applied to my media literacy agenda in Images \& Power. I decided to omit one educational film from the course syllabus and replace it with a unit on ABR. Students were assigned about two-thirds of the book Method Meets Art:Arts-Based Research Practice (Leavy, 2009) and one class period was devoted to reviewing it. I then incorporated an arts-based component into their final mass media research papers. In addition to their conventional research paper they were now required to represent some aspect of their work using an artsbased approach (collage, poem, script) with a brief artist-researcher statement explaining their project. As described in the course syllabus the students' mass media research paper assignment is as follows:

Your final paper/project will be a 6-8 page single authored analytical reflection on a media-based topic of your own choosing, for which you will conduct a literature review and incorporate course readings and/or films. The first part of this assignment can be done in a variety of ways. You can present a traditional literature review on your topic (it may be sociologically grounded or interdisciplinary); you can construct a thesis statement and write a paper based on your thesis; you can conduct a small scale research project in which you carry out a content analysis or some other method of original data gathering and analysis; you can write a debate paper; you can write a paper weaving together a selection of course readings; or many other options (feel free to discuss your ideas with me). You are not being graded on your opinions (whether or not you agree with the authors whose work you engage with); however, you are being graded on your critical engagement with the ideas and themes presented in the material you use-be reflective and analytical. Show how course materials and your own literature review have encouraged you to unravel your own assumptions. However you approach the paper, you need to demonstrate that you have in some way grappled with the ideas presented in this course. The paper must also contain an arts-based component. In other words, you will use an arts-based approach to representing some of your themes (i.e., collage with media clips, poetry, a performance script, etc.). We will be reviewing artsbased approaches to research before this assignment is due. Your readings in this area should be clearly evidenced in your final paper/project. For 
example, a collage in which you randomly tack some media images onto a piece of cardboard would not be appropriate. Rather, use one of the collagemaking strategies reviewed or create and explain your own strategy. What data will be included? How will images be juxtaposed to each other? Will words be used? If so, in what ways? What are the various interpretations of your collage? Does your collage reinforce or challenge your paper or some theme there within? Think outside the box-feel free to develop an artsbased approach beyond those we have reviewed in class. The most important thing to consider is the relationship between the paper and the arts component: is there reinforcement, magnification, tension, and/or something else altogether?

The resulting work was outstanding. Significantly, although some were initially apprehensive about doing something "arty," the result was a much higher performance level on the traditional paper. I believe this is because students became more invested in their projects. I now turn to some examples of student work and then I review the advantages of the ABR component in relation to course goals. Students mentioned by name were contacted and enthusiastically agreed to have their work included.

\section{Illustrations of Student Work}

The students in my Images \& Power course tackled a diverse range of topics pertaining to media (and demonstrating their media literacy) and they created many different kinds of arts-based projects to go along with their final papers. For example, one student wrote his paper about how issues pertaining to the American dream circulate via advertising. He ultimately argued, and quite convincingly, that the American dream has been systematically linked to consumption via the media. His ABR component was a three-dimensional work of art. He took an apple pie box and decorated the borders with American flag imagery and phrases/slogans. Inside of the box he created a multi-dimensional arrangement of various items including toy soldiers, a slice of pie, and so forth. Another student conducted a content analysis of the ways in which environmental issues are dealt with (or made invisible) by advertising. For her ABR component she created a large green leaf-shape backdrop out of posterboard. On one side of the leaf she created an intricate collage out of advertisements. On the other side she wrote a poem about how the media makes consumption attractive and renders environmental consequence invisible. The poem was followed by an artist statement explaining her project and how it "opened her eyes." 
The poem that opened this paper was a part of Sean Lynch's paper about the media's negative portrayal of feminism, which he argued makes college students fear the label. His paper weaved together several course readings and examined the media's treatment of gender with respect to the female beauty ideal as well as the portrayal of women in public spheres (such as politics and sports). His ABR component consisted of a set of five original poetic works. The poems all deal with issues of female and male identity struggles within a mass-mediated context. The two poems that follow are largely inspired by Deborah Tannen's reading "There is No Unmarked Woman" and the film "Dream Worlds 3," which analyzes the objectification of women in music videos.

\section{"The Dress" by Sean Lynch}

She exits

Looking in on the girl wearing her dress

Watches as she grows up

Growing, slowly-into it

No matter what she learned, what she said

What she wanted, who she met

That dress told him

How smart she was, how far she'd been-that she liked men

It let slip her view on the right to choose

That she only watched tv for the news

It whispered to him her secret past

Of relationships that never last

Everything he wants to know her dress would surely tell him so

Utterly exposed speech has decomposed

The firm marked grip of helplessness around her waist

It ravaged through her confidence

Groped her self-esteem

Dragged her back into dress

Silenced her righteous scream 
It stripped her of her independence

Forced itself upon her

Leaving a stale resonance

Dark and deep within her

Out of breath and out of voice

She sees what has occurred

Need not set the record straight

Her dress will say the word

\section{"Ideology of Love" by Sean Lynch}

You would love me

You would love me and hold me tenderly

Love me and squeeze me

And never leave me

You might sing to me-it could be a Coldplay song

That's what love is that's how you show it

With songs and notes

And anchored feelings

That never float

I give my origami heart to you

Complexly created

But easy to un-do

You'll tell your friends I'm yours to keep

But cool and hot-the double threat

I'm like a guy to hang out with

Like a guy

I won't make you made or be annoying

Won't ever be sad

And pretend I'm enjoying 
The attention that you give

Your feigned interest in love

I'll be your Mrs. You

You'll be all I have

It'll be my identity for which I grab

We've taken our vows

Through sickness or health

I've taken my final bow

As my true self

My final examples come from two students who created "booklets" along with their papers.

Charlotte Tuminelli wrote her paper about the effects of mass-mediated consumer culture on the psychic life of the individual. For her ABR component she created a "Diary of Discontentment." The collage-style book was made with a handpainted cardboard cover, marked with magazine images including a diamond ring, a donut, a swing set, money and other images.

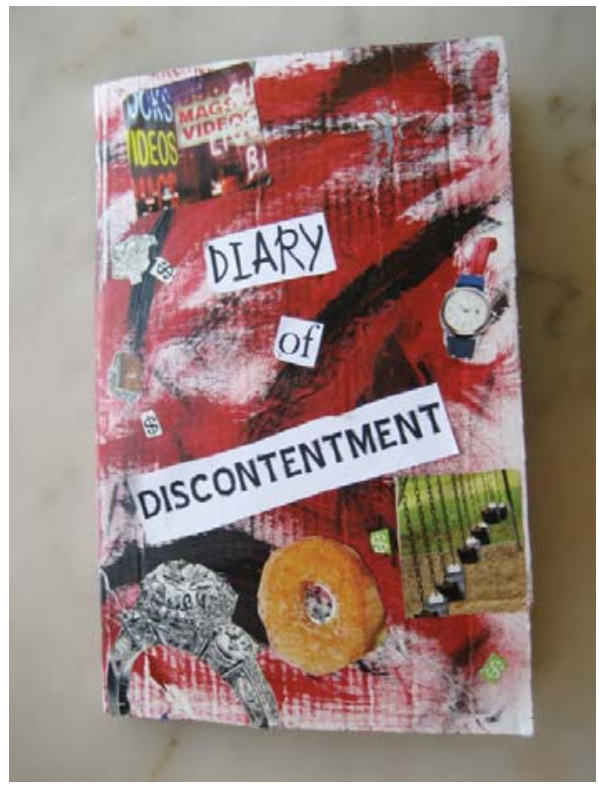

Fig. 1: Diary of discontentment 
The intricate book uses a cut-out approach in which one page has a square cut out of the middle. The border is decorated with images and phrases collected from media sources and the cut-out presents a window into the next page.

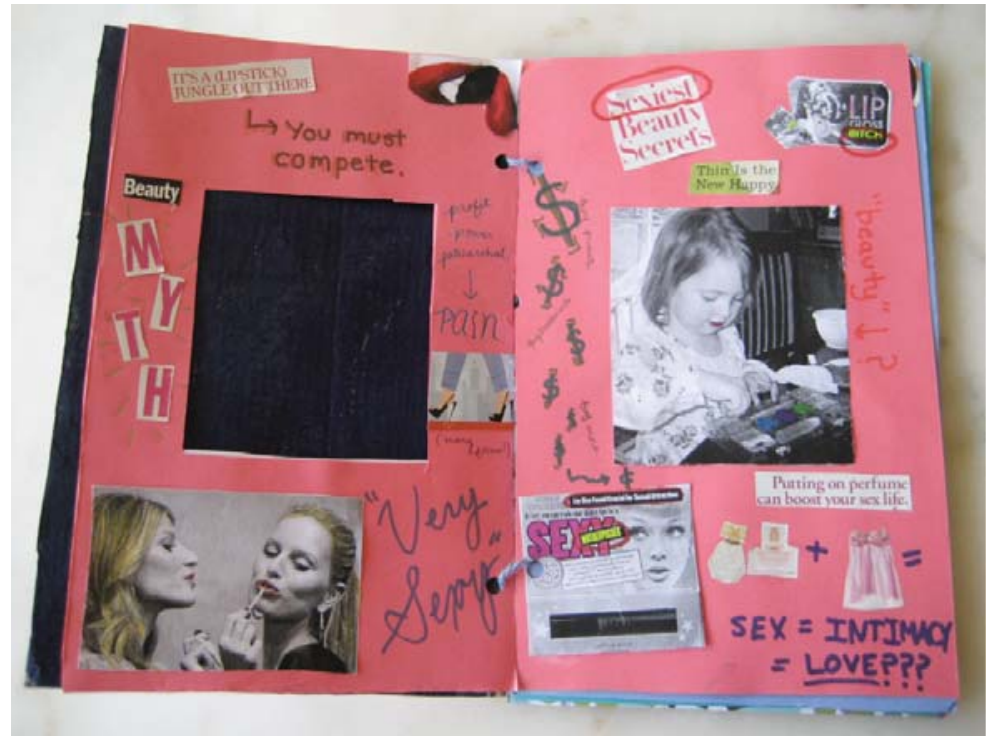

Fig. 2: Cut-out approach

Each set of pages has a theme. The themes include: cosmetics and attraction; the commodification of "magic" and happiness; and mass production (including the effect on consumers and workers in a globalized context). The thirteenth and final page offers a quote by 1920s singer Margaret Young: “Often people attempt to live their lives backwards; they try to have more things, or more money, in order to do more of what they want, so they will be happier."

Diane Tobio wrote her paper about the role of media in creating "girl culture." For her ABR component she made a collage-style booklet titled "When I Grow Up," designed to be read by young girls. She created a mosaic-style cover using bright paper clippings and images that might appeal to young girls, such as butterflies (imagery which also works on the level of metaphor) and outlined the title with colorful glitter, again appealing to young girls. 


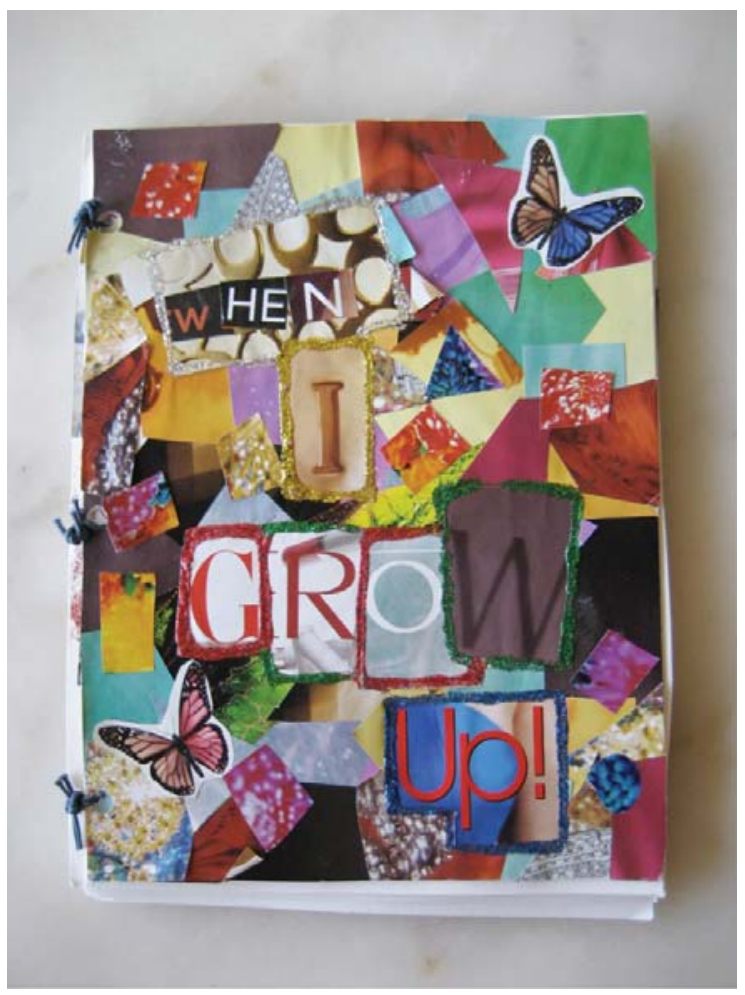

Fig. 3: When I grow up

Each page in the booklet is inspired by a particular reading from the class, and is so labeled. The top of each page states: "When I grow up..." and then presents a collage of magazine clippings (imagery and words) focused on a particular theme. Beneath the collage reads an affirmative, positive, empowering statement. The themes include: women having opportunities in politics, freedom with respect to love and sexuality, a celebration of physical uniqueness, women having opportunities in the economy, and the falsity of television's portrayal of women. 


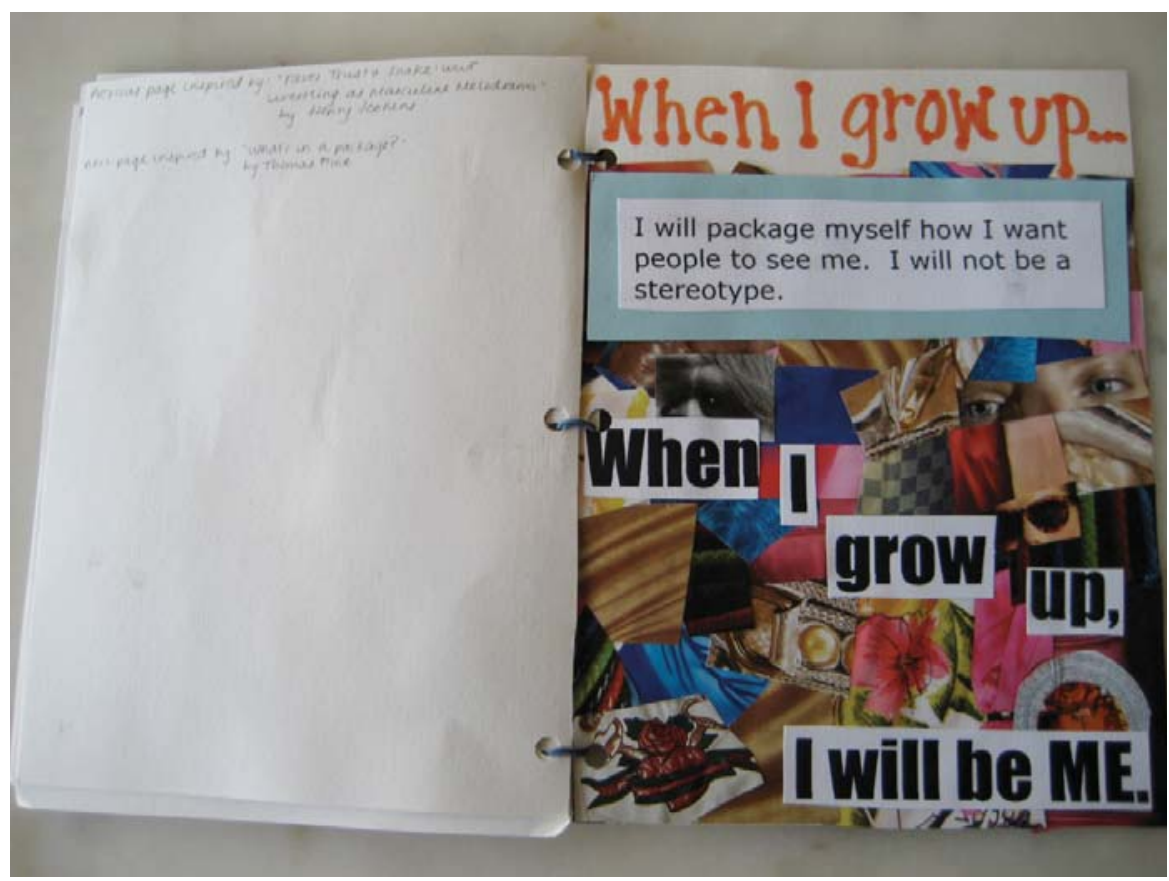

Fig. 4: Sample page

The last page says:"When I grow up... I will package myself how I want people to see me. I will not be a stereotype. When I grow up, I will be ME." Clearly the message of Tobio's work is empowerment education for the next generation of girls.

\section{Advantages of ABR as a Media Literacy Teaching Tool in Images \& Power}

As the preceding examples indicate, the arts-based component allowed the students to do several things: 1. make micro-macro linkages (typically using personal perspectives and experiences), 2. see connections between different dimensions of media and the visions of social reality they create, and 3. focus on issues of social power (race, class, gender, sexuality, nationality). All of these factors together increased their media literacy and fostered the development of a critical consciousness. Looking at the highly personalized autoethnographic approaches most students elected to apply to their projects (in which they demonstrated a far greater understanding of the media than at the beginning of the semester), I believe students experienced consciousness-raising and hopefully empowerment. Student course evaluations as well as unsolicited comments (made in person and via e-mail) confirm that students felt more sensitized and empowered. 


\section{Conclusion}

ABR was a powerful tool in my media literacy curriculum. With minimal effort on my part, and virtually no reduction in standard course content, the addition of ABR greatly increased student learning and engagement. The ABR work involved active, engaged student learning (rather than the passive learning that characterizes a great deal of lecture and film viewing approaches to pop culture courses). As the teaching and learning literature indicates, and as my own teaching over the years has confirmed, active learning leads to more in-depth and meaningful learning. With respect to media literacy and consciousness-raising, there is no doubt that learning by seeing and doing is invaluable to students. In my experience using ABR in Images \& Power, students both learned "more" and also learned the traditional material better. Arts-based practices will continue to serve as a part of my holistic approach to student learning.

I intend to incorporate especially designed, problem-centric, ABR projects into my sociology of gender elective and required research methods courses. I plan to systematically record my impressions regarding the impact on student learning. Further, I will compare the effectiveness of $A B R$ in elective versus required courses and the ways that ABR can be used to accomplish different desired learning outcomes. I hope that my experiences can be used as a springboard for others considering $A B R$ as a teaching strategy.

\section{Notes}

1. Thank you to the students in my "Images \& Power: Popular Culture" and "Research Methods in Sociology" courses. In particular, thank you to Sean Lynch, Diane Tobio, and Charlotte Tuminelli for allowing me to share their work. 


\section{References}

Berel, S., \& Irving, L. M. (1998). Media and disturbed eating: An analysis of media influence and implications for prevention. The Journal of Primary Prevention. 18(4) 415-430.

Bergsma, L. (2004). Empowerment education: The link between media literacy and health promotion. American Behavioral Scientist, 48(2), 152-164.

Brookfield, S. (2006). The skillful teacher: On technique, trust, and responsiveness in the classroom. Jossey-Bass.

Brown, J. A. (1998). Media literacy perspectives. Journal of Communications. 48(1) 44-56.

Dream Worlds 3 (2007). Produced by Media Education Foundation. Desire, Sex \& Power in Music Video [DVD]. By Sut Jhally.

Eisner, E. (2008). Commentary: What education can learn from the arts. LEARNing Landscapes. 2(1) 23-30. Retrieved October 7, 2009, from http://www.learnquebec.ca /en/content/learninglandscapes/vol2no1. html

Finkel, D. (2000). Teaching with your mouth shut. Boynton/Cook.

Greene, M. (2008) Commentary: Education and the arts: The windows of imagination. LEARNing Landscapes. 2(1) 17-21. Retrieved October 7, 2009, from http://www.learnquebec.ca/en/content/ learninglandscapes/vol2no1.html

Hershorn, K. (2005). Learning through arts-based action research: Creative approaches to destructive dynamics in our schools and in our world. Paper presented at the International Congress of Qualitative Inquiry. Urbana-Champaign, IL. hooks, b. (1994). Teaching to transgress: Education as the practice of freedom. Routledge.

Irving, L. M., \& Berel, S. R. (2001). Comparison of media literacy programs to strengthen college women's resistance to media images. Psychology of Women Quarterly, 25(2), 103-111.

Knowles, J. G., \& Thomas, S. M (2002). Artistry, inquiry, and sense-of-place: Secondary school students portrayed in context. In C. Bagley \& M. B. Cancienne (Eds.), Dancing the Data, (121-132). New York: Peter Lang.

Leavy, P. (2009). Method meets art: Arts-based research practices. New York: Guilford Press.

Levine, M. P., \& Smolak, L. (1998). The mass media and disordered eating: Implications for primary prevention. In W. Vandereycken \& G. Noordenbos (Eds.) The Prevention of Eating Disorders (23-56). London: The Anthlone Press.

Levine, M. P., Piran, P., \& Stoddard, C. (1999). Mission more probable: Media literacy, activism, and advocacy as primary prevention. In N. Piran, M. P. Levine \& C. SteinerAdair (Eds.), Preventing eating disordersa handbook of interventions and special challenges (3-25). University of Toronto: Brunner/Mazel.

Tannen, D. "Marked Women, Unmarked Men." The New York Times Magazine, June 20, 1993, 18, 52, 54.

Young, M. Retrieved October 7, 2009, from http://www.brainyquote.com/quotes/ quotes/m/margaretyo207324.html. 


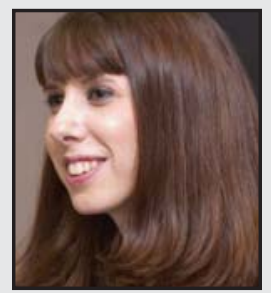

Patricia Leavy is Associate Professor of Sociology at Stonehill College in Easton, MA. She is the author of Iconic Events: Media, Politics, and Power in Retelling History (2007) and Method Meets Art: Arts-Based Research Practice (2009). She is the coauthor of Feminist Research Practice (2007) and The Practice of Qualitative Research (2005). She is the co-editor of Hybrid Identities:Theoretical and Empirical Examinations (2008), Handbook of Emergent Methods (2008), Emergent Methods in Social Research (2006), and Approaches to Qualitative Research (2004).

\section{LINK TO:}

http://www.stonehill.edu/x9211.xml 